\title{
Experimental Study on Efficiency of Floating Vertical Axis Wind Turbine with Variable-Pitch
}

\author{
Jae-Heui Kim*, Hyo-Jae Jo ${ }^{* *}$, Jae-Hyuk Hwang ${ }^{* *}$, Min-Suk Jang ${ }^{* *}$ and Byeong-Seong Lee ${ }^{* * *}$ \\ "Division of Naval Architecture and Ocean Systems Engineering, Korea Maritime and Ocean University, Busan, Korea \\ *cean Science and Technology School, Korea Maritime and Ocean University, Busan, Korea \\ ${ }^{*}$ Research Institute of Medium and Small Ship-Building, Busan, Korea

\section{부유식 가변 피치형 수직축 풍력발전기의 발전효율에 관한 실험 연구} \\ 김재희 ${ }^{*}$ 조효제 $0^{* *}$ 황재혁 ${ }^{* *}$ 장민석** - 이병성 ${ }^{* * *}$ \\ "한국해양대학교 조선해양시스템공학부 \\ "한국해양대학교 해양과학기술전문대학원 \\ 중소조선연구원
}

KEY WORDS: Variable-pitch 가변 피치, Vertical axis wind turbine 수직축 풍력발전기, Model test 모형시험, Mechanical power test 기 계적 출력 실험

\begin{abstract}
This paper presents the efficiency of a floating vertical axis wind turbine with variable-pitch. A model was designed to use the lift force and drag force for blades with various pitch angles. The blade's pitch angle is controlled by the stopper. To validate the efficiency of the wind turbine discussed in this paper, a model test was carried out through a single model efficiency experiment and wave tank experiment. The parameters of the single model efficiency experiment were the wind speed, electronic load, and pitch angle. The wave tank experiment was performed using the most efficient pitch angle from the results of the single model efficiency experiment. According to the results of the wave tank experiment, the surge and pitch motion of a structure slightly affect the efficiency of a wind turbine, but the heave motion has a large effect because the heights of the wind turbine and wind generator are almost the same.
\end{abstract}

\section{1. 서 론}

최근 무분별한 화석 에너지 사용에 따른 자원 고갈 및 지구온 난화 문제로 신재생 에너지에 관한 관심과 수요가 증대되었다. 그 중 풍력 에너지는 한때 경제적 효율성을 갖추지 못해 주목 받지 못했지만, 오늘날 관련 기술의 발달로 효율성이 증대되어 전 세계적으로 주목받고 있다. 특히 유럽 및 미국과 같은 기술 선진국에서는 이미 소형풍력발전 시스템부터 $5 \mathrm{MW}$ 급 이상의 대형풍력발전 시스템까지 개발이 완료되어 실증 단계에 있다. 하지만 풍력발전 시스템의 대형화는 소음, 전파, 경관 등의 민 원문제를 발생시킨다. 또한 우리나라와 같이 협소한 국토로 인 한 육상풍력발전 보급 제한은 풍부한 부지, 양질의 풍력자원을 이용할 수 있고 민원문제를 해결할 수 있는 해상풍력발전에 대 한 관심을 증가시켰다.

풍력발전의 원리는 바람이 갖는 운동에너지(Wind kinetic energy)
를 터빈을 통해 기계적 에너지로 변환시키고, 변환된 기계적 에 너지를 다시 전기에너지로 변환시키는 것이다. 일반적으로 풍 력발전기는 기동풍속(Cut-in wind speed)과 정격풍속(Rated wind speed) 사이에서 풍속의 세제곱과 터빈의 면적에 비례하는 에너 지를 생성하고, 정지풍속(Cut-out wind speed)까지 일정한 출력 이 유지되다가 그 이상이 되면 시스템의 안전을 위하여 멈추도 록 설계된다.

풍력발전기는 회전축의 방향과 형상에 따라 수평축 풍력발전 기(Horizontal axis wind turbine, HAWT)와 수직축 풍력발전기 (Vertical axis wind turbine, VAWT)로 분류 된다. 수평축 풍력발 전기는 수직축 풍력발전기에 비해 풍속 대비 효율은 높으나, 바 람의 방향과 각도에 따라 그 효율이 크게 좌우되어 요 시스템 (Yaw system) 혹은 꼬리날개가 필요하기 때문에 구조적으로 복 잡해지는 단점이 있다. 수직축 풍력발전기는 바람의 방향에 영 향을 받지 않아 요 시스템이 필요하지 않고 비교적 낮은 풍속

Received 2 January 2018, revised 18 May 2018, accepted 7 June 2018

Corresponding author Hyo-Jae Jo: +82-051-410-4302, hjjo@kmou.ac.kr ORCID: http://orcid.org/0000-0002-7847-0462

(c) 2018, The Korean Society of Ocean Engineers

This is an open access article distributed under the terms of the creative commons attribution non-commercial license (http://creativecommons.org/licenses/by-nc/3.0) which permits unrestricted non-commercial use, distribution, and reproduction in any medium, provided the original work is properly cited. 
의 바람과 풍향에 관계없이 발전이 가능하다는 장점이 있다. 특 히 우리나라와 같이 기후변화가 심하고 계절풍의 영향을 받는 지역은 수직축 풍력발전기가 수평축 풍력발전기에 비해 더 유 용하다(Sim, 2013).

수직축 풍력발전시스템에 대한 선행연구로 Sheldahl and Klimas(1981)은 서로 다른 에어포일을 적용한 수직축 풍력발전 기의 레이놀즈 수에 따른 공력특성을 파악하였다. Martin(2011) 은 NREL $5 \mathrm{MW}$ 급 해상용 풍력발전기를 $1 / 50$ 로 축소 제작하여 실험을 실시하였고, 실험 결과를 통해 부유식 풍력발전기의 효 율을 분석하기 위한 시뮬레이션 코드를 검증 하였다. Oh and $\operatorname{Kim}(2012)$ 은 해양용 소형 수직축 풍력발전기를 설계하고 파랑 및 바람으로 인한 구조물 운동응답이 발전효율에 미치는 영향 을 파악하였다. Kim et al.(2011)은 5MW급 스파(Spar)타입 부유 식 해상 풍력발전시스템의 파랑 및 바람 중 구조물의 운동성능 을 수치해석 결과와 모형시험 결과를 비교하였다.

일반적으로 항력을 이용하는 수직축 풍력발전기는 토크가 큰 반면 발전 효율이 매우 낮고 양력을 이용하는 수직축 풍력발전 기는 높은 풍속에서는 발전 효율이 좋으나 낮은 풍속에서는 기 동이 어렵고 효율이 매우 낮은 단점이 있다. 본 연구에서 사용 한 가변 피치형 수직축 풍력발전기는 블레이드에 대한 바람의 방향과 로터의 회전에 따른 원심력에 의하여 블레이드의 피치 각이 시시각각 자율적으로 조정됨에 따라, 양력과 항력 모두를 회전력으로 전환시켜 발전효율이 증가하도록 설계하였다.

본 연구에서는 자체 개발한 가변 피치형 수직축 풍력발전기 의 단독 발전효율 성능을 파악하기 위해 풍동실험을 실시하였 고, 원형실린더 형태의 부유체와 결합 후 파랑과 바람 중 부유 체의 운동에 따른 발전효율 성능을 수조실험을 통해 파악하였 다. 단독 발전효율 실험에선 블레이드의 피치 가변 범위에 따른 분당회전수(Revolutions per minute, RPM)와 기계적 출력(Power) 을 비교 - 분석 하였다. 부유식 풍력발전 실험에서는 단독효율 실험결과 중 가장 우수한 발전 성능의 피치 가변 범위에 대해 파랑과 바람 중 부유체 운동이 발전효율에 미치는 영향을 비교 - 분석 하였다.

\section{2. 풍력발전의 이론적 해석}

바람은 공기라는 질량을 가지는 물질의 운동이므로 운동에너 지 공식으로 바람의 운동에너지를 정의할 수 있다. 공기의 질량 을 $m(\mathrm{~kg})$, 속도를 $v(\mathrm{~m} / \mathrm{s})$ 라고 할 때 바람의 운동에너지 $E$ 는 식 (1)과 같다.

$$
E=\frac{1}{2} m v^{2}
$$

질량 흐름률(Mass flow rate) $\dot{m}$ 은 공기밀도 $\rho\left(\mathrm{kg} / \mathrm{m}^{3}\right)$ 와 풍속 $v$ $(\mathrm{m} / \mathrm{s})$ 그리고 바람의 방향과 수직인 블레이드의 면적 $A\left(\mathrm{~m}^{3}\right)$ 의 곱으로 식 (2)와 같이 나타낼 수 있다.

$$
\dot{m}=\frac{d m}{d t}=\rho A v
$$

공기의 흐름에 의한 에너지 출력 $P(\mathrm{~W})$ 는 단위시간당 에너지 의 변화량으로 정의되고 운동에너지 식을 출력으로 변형시키면 식 (3)과 같다.

$$
P=\frac{d E}{d t}=\frac{d}{d t}\left(\frac{1}{2} m v^{2}\right)=\frac{1}{2} \frac{d m}{d t} v^{2}
$$

따라서 식 (1)에 식 (2)를 대입하면 바람에 의한 에너지 출력 $P(\mathrm{~W})$ 는 식 (4)와 같다.

$$
P=\frac{1}{2} \rho A v^{3}
$$

블레이드의 기계적 출력 $P_{\text {mechanical }}$ 은 토크 $T(\mathrm{~N} \cdot \mathrm{m})$ 와 풍력 발전기의 회전 각속도 $\omega(\mathrm{rad} / \mathrm{s})$ 의 곱으로 식 (5)와 같이 정의할 수 있다. 풍력발전기의 회전 각속도를 분당 회전수 RPM으로 환 산하여 계산하면 식 (6)과 같다(Hwang, 2014).

$$
\begin{aligned}
& P_{\text {mechanical }}=T \cdot \omega \\
& P_{\text {mechanical }}=T \cdot R P M \cdot \frac{\pi}{30}
\end{aligned}
$$

풍력발전기의 출력 성능을 평가하는 방법에는 발전기의 전력 을 측정하는 방법과 회전축의 토크를 측정하는 방법이 있다. 발 전기의 전력을 측정하면 기계적 손실과 전기적 손실을 모두 고 려한 전력을 측정할 수 있다는 장점이 있다. 회전축의 토크를 측정하는 방법은 블레이드에서 회전축의 토크로 전환되는 효율 만을 평가할 수 있다. 즉 회전축의 토크를 전기 에너지로 변환 하며 생기는 변수를 무시할 수 있다는 장점이 있다(Lee, 2014). 본 연구에서는 풍력발전기의 출력 성능을 평가하기 위해 기계 적인 효율만을 평가하는 회전축의 토크를 측정하는 방법을 사 용하였다.

\section{3. 실 험}

실험 모델의 블레이드 길이는 $0.28 \mathrm{~m}$, 폭은 $0.225 \mathrm{~m}$ 이고 블레이 드의 형상은 Fig. 1과 같다. 블레이드 상-하판(Top and bottom plates)의 지름은 $0.5 \mathrm{~m}$ 로 제작되었고 총 5 엽의 블레이드를 원형 판의 중심으로 부터 $0.22 \mathrm{~m}$ 떨어져 있는 위치에 결합하였다. 코 드길이는 $0.225 \mathrm{~m}$, 앞전부터 회전축 중심까지의 거리와 무게중 심까지의 거리는 각각 $0.065 \mathrm{~m}, 0.096 \mathrm{~m}$ 이다. 블레이드는 알루미 늄(Aluminium)재질로 블레이드 상 - 하판은 충격강도가 크고 가 벼운 폴리카보네이트(Polycarbonate)재질로 제작하였다. 또한 블 레이드의 피치 가변 범위를 제어하기 위해 블레이드 상판에 고 정나사를 삽입한 스토퍼(Stopper)를 설치하였다.

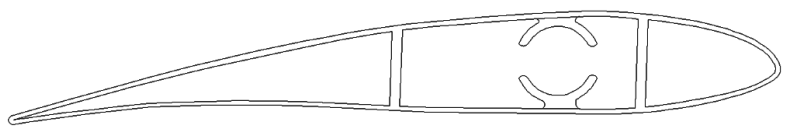

Fig. 1 Shape of the blade 


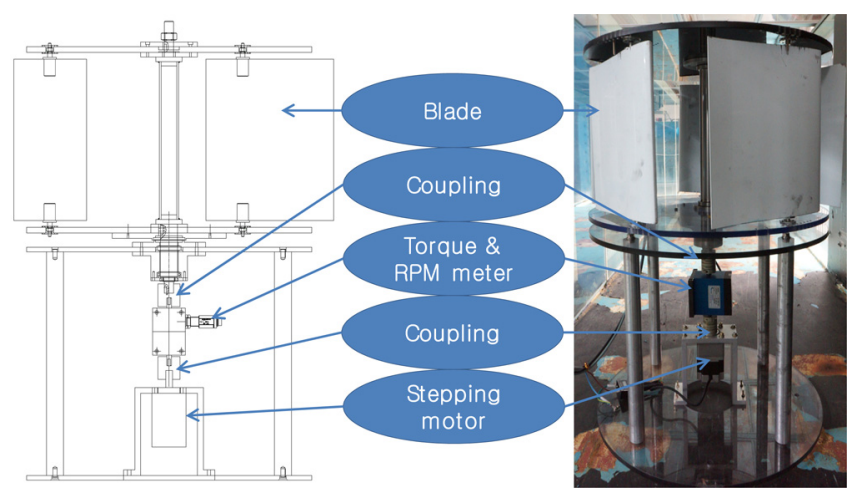

Fig. 2 Mechanical measuring systems

본 연구에 사용된 풍력발전기의 기계적 출력을 측정하는 실 험 장비는 RPM과 토크를 동시에 측정할 수 있는 토크센서와 측정값을 실시간으로 확인할 수 있는 모니터로 이루어져 있으 며, 전기적 부하 장치로 스테핑 모터(Stepping motor)를 장착하 여 Fig. 2와 같이 구성하였다.

Fig. 3 은 로터의 회전에 따른 블레이드 1 개의 움직임을 위치 별로 도식화 한 것이다. 블레이드의 유선형 단면을 따라 흐르는 바람에 의한 양력구간, 블레이드가 바람의 저항을 받아 생기는 항력구간, 블레이드가 회전하며 양력구간과 항력구간이 연결되

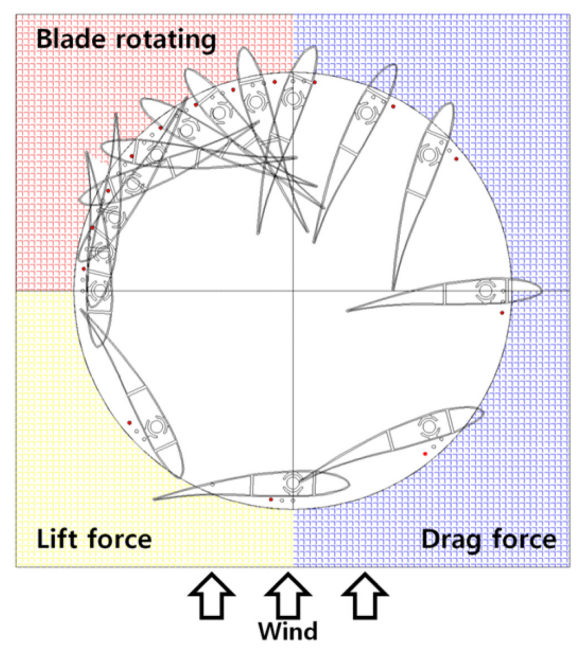

Fig. 3 The condition of the blade position following one rotation

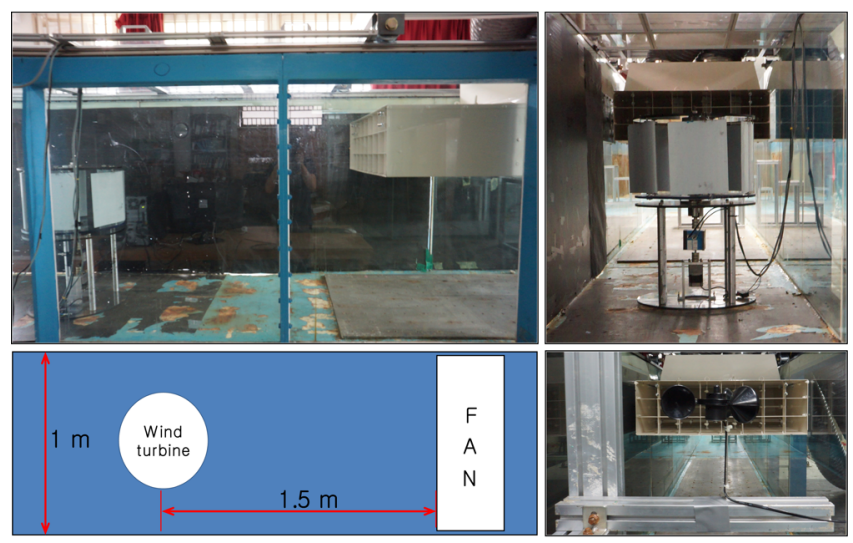

Fig. 4 Configuration of the single VAWT experiment
는 날개회전구간으로 구분 할 수 있다. 일반적으로 수직축 풍력 발전기는 양력 혹은 항력 중 하나만을 사용한다. 그러나 자체 개발한 수직축 풍력발전기는 바람 및 원심력에 의해 블레이드 피치각이 시간에 따라 변화하면서 양력과 항력 모두를 회전력 으로 전환시켜 최적의 에너지 변환 효율을 낼 수 있도록 설계 되었다.

풍력발전기 단독 발전효율 실험을 위해 Fig. 4와 같이 한국해 양대학교 해양시스템연구실의 2 차원 조파수조를 활용하여 간이 형 풍동실험(Wind tunnel test) 환경을 조성하였다.

바람 발생장치에서 생성된 바람이 2 차원 조파수조를 따라 균 일하게 흐를 수 있도록 조파수조 상단부에 덮개를 설치하였다. 또한 후류에 발생하는 바람 에너지를 최소화하기 위하여 풍력 발전기와 벽 사이에 약 $15 \mathrm{~m}$ 의 공간을 두었다. Table 1 은 단독 발전효율 실험 조건을 나타내고, Fig. 5 는 각 실험 조건에 따른 피치 가변 범위를 나타내고 있다. 실험 풍속 범위는 $1 \mathrm{~m} / \mathrm{s}$ 간격 으로 $3 \sim 10 \mathrm{~m} / \mathrm{s}$ 이고 풍력터빈의 위치에서 5 분간 3 회에 걸쳐 측정 한 값을 평균 하였다.

실험은 전기적으로 무부하 상태 그리고 부하상태에 대하여 수행되었다. 무부하 상태에서는 전기적인 부하의 연결이 없기 때문에 발전기 베어링 마찰을 제외한 순수 풍력발전기의 공력 성능을 측정할 수 있다. 따라서 전기적 부하 없이 풍속별 RPM 을 측정함으로써 터빈의 회전이 시작되는 풍속인 기동풍속 (Cut-in speed)을 측정할 수 있다. 실제 해상풍력 발전기의 경우 초기 기동풍속을 낮추기 위해 코깅토크를 저감시키는 다양한 장치가 사용된다. 그러나 본 연구에서는 축소 제작된 실험 모델 의 특성상 코깅토크 저감 장치를 사용할 수 없어 수동으로 스 테핑 모터의 전기적 부하 여부를 선택하여 실험을 수행하였다.

Table 1 Design parameters for experimental condition in wind tunnel

\begin{tabular}{ccc}
\hline \hline $\begin{array}{c}\text { Wind speed } \\
{[\mathrm{m} / \mathrm{s}]}\end{array}$ & $\begin{array}{c}\text { Variable-pitch range } \\
{[\mathrm{deg}]}\end{array}$ & Electronic Load \\
& $-35 \sim+25$ & \\
& $-15 \sim+65$ & $\mathrm{X}$ \\
& $-10 \sim+105$ & \\
$3 \sim 10$ & $-35 \sim+25$ & $\mathrm{O}$ \\
& $-15 \sim+65$ & \\
& $-10 \sim+105$ & \\
\hline
\end{tabular}

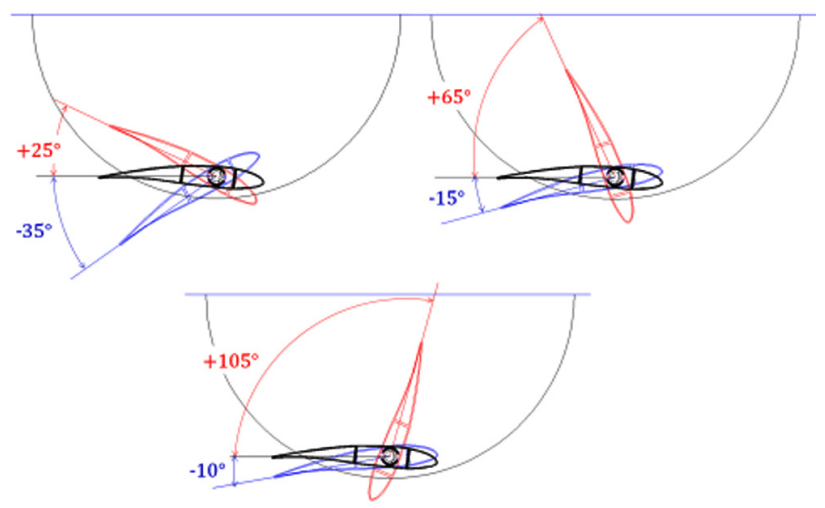

Fig. 5 Variable-pitch range of the blade 

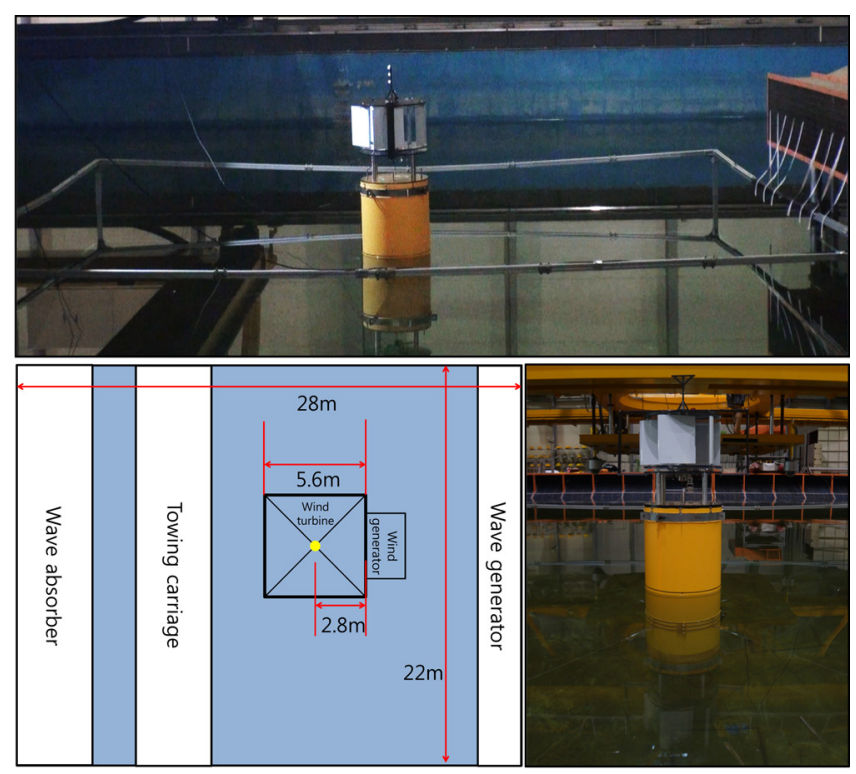

Fig. 6 Configuration of the floating VAWT experiment

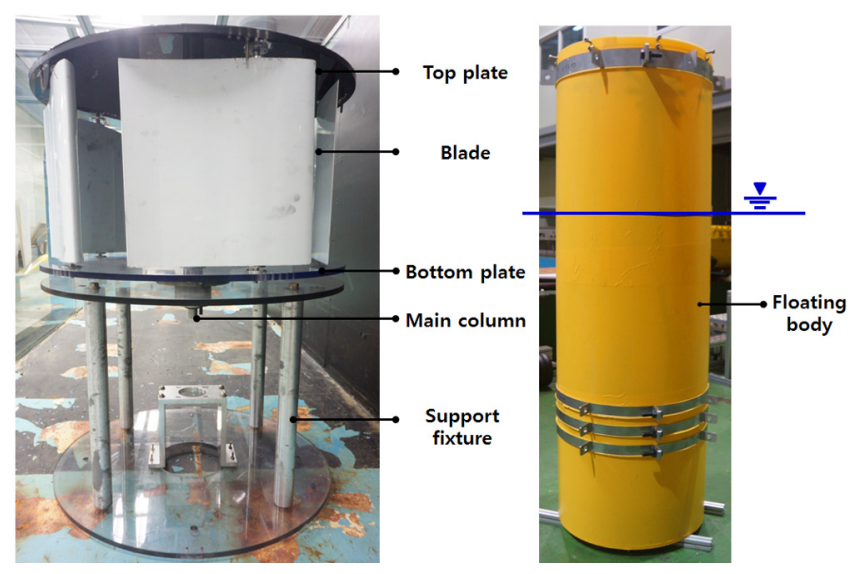

Fig. 7 Prototype of the wind turbine and the cylindrical type floating body

본 실험에서 사용된 풍력발전기는 자체 개발하였다. 실증단계 전 사전연구로서 축소모형 수준에서의 성능을 파악하기 위해 설 계되고 제작되었다. 부유식 풍력발전 실험은 Fig. 6과 같이 중소 조선연구원(Research Institute of Medium \& Small Shipbuilding)의 길이 $28 \mathrm{~m}$, 폭 $2 \mathrm{~m}$, 수심 $2 \mathrm{~m}$ 의 해양 공학수조에서 진행하였다. 부 유식 풍력발전에 적용된 부유체는 Fig. 7과 같이 원형실린더 형 태의 구조물로, 다른 형태의 구조물보다 흘수가 깊어 상대적으 로 상하동요에 대한 응답성능이 좋다는 장점이 있다. 그러나 무 게중심의 위치가 구조물의 운동성능을 크게 좌우하기 때문에 무 게중심을 낮추기 위해 토크센서를 제거하고 지지부(Support fixture)의 길이를 최소화하여 풍력발전기를 경량화 하였다. 경량 화를 위해 토크센서를 제거하였기 때문에 비접촉식 RPM 측정 기를 이용해 RPM을 측정하여 각 실험조건에 대해 비교하였다.

Table 2는 부유식 풍력발전 각 실험 조건들을 나타낸다. 실험 풍속은 $8 \mathrm{~m} / \mathrm{s}$ 로 풍력터빈 위치에서 5 분간 3 회에 걸쳐 측정한 값 을 평균하였다. 규칙파(Regular wave) 실험은 $1.6 \mathrm{sec}$ 부터 $3 \mathrm{sec}$ 까지 $0.2 \mathrm{sec}$ 간격으로 8 개의 규칙파에 대해 실시하였으며, 불규칙파
Table 2 Design parameters for experimental condition in wave tank

\begin{tabular}{ccc}
\hline \hline $\begin{array}{c}\text { Variable-pitch range } \\
{[\mathrm{deg}]}\end{array}$ & Wave type & $\begin{array}{c}\text { Wind speed } \\
{[\mathrm{m} / \mathrm{s}]}\end{array}$ \\
\hline & - & \\
$-10 \sim+105$ & $\begin{array}{c}\text { Regular wave } \\
\text { Irregular wave }\end{array}$ & 8 \\
& \\
\hline
\end{tabular}

(Irregular wave)는 유의파고( $H_{1 / 3}$, Significant wave height) $0.1235 \mathrm{~m}$ 와 평균주기( $T$, Mean period) $1.76 \mathrm{sec}$ 인 ITTC(International towing tank conference)스펙트럼을 사용하였다. 파랑 조건은 구조물의 주파수영역 수치해석 결과를 바탕으로 실험 수조의 조파 범위 내에서 구조물의 운동을 전반적으로 관찰 할 수 있는 조건으로 선정하였다.

\section{4. 실험결과 및 고찰}

\section{1 단독 발전효율 실험}

Fig. 8은 기동풍속을 측정하기 위해 전기적 무부하 상태에서 풍속별 RPM만을 측정한 결과이다. 실험결과 모든 피치 가변 범 위에서 풍동시스템의 최저 풍속 $3 \mathrm{~m} / \mathrm{s}$ 일 때 최초기동이 일어남 을 확인 하였다. 또한 모든 피치 가변 범위에서 풍속이 증가함 에 따른 RPM 증가의 양상은 비슷한 경향을 보였고 이로서 피 치 가변 범위가 기동풍속을 낮추는 것에는 거의 영향을 주지 않음을 확인 하였다. 피치 가변 범위 중 $-10^{\circ} \sim+105^{\circ}$ 의 경우가 가장 높은 RPM 결과를 나타내었다.

Fig. 9는 전기적 부하 상태에서 피치 가변 범위에 따라 풍속 별 출력 결과값을 나타내었다. 앞선 실험결과와 마찬가지로 피 치 가변 범위 $-10^{\circ} \sim+105^{\circ}$ 의 경우 가장 높은 출력을 가지고 가 장 낮은 풍속에서 발전이 시작된다. 따라서 본 연구에서 사용된 가변 피치형 수직축 풍력 발전기는 가변 범위 $-10^{\circ} \sim+105^{\circ}$ 의 경 우가 최대 효율을 가지는 것을 확인하였다. 또한 풍속이 증가할 수록 피치 가변 범위에 따른 발전 가능 풍속범위와 발전 효율 의 차이가 커지는 것을 확인 할 수 있다.

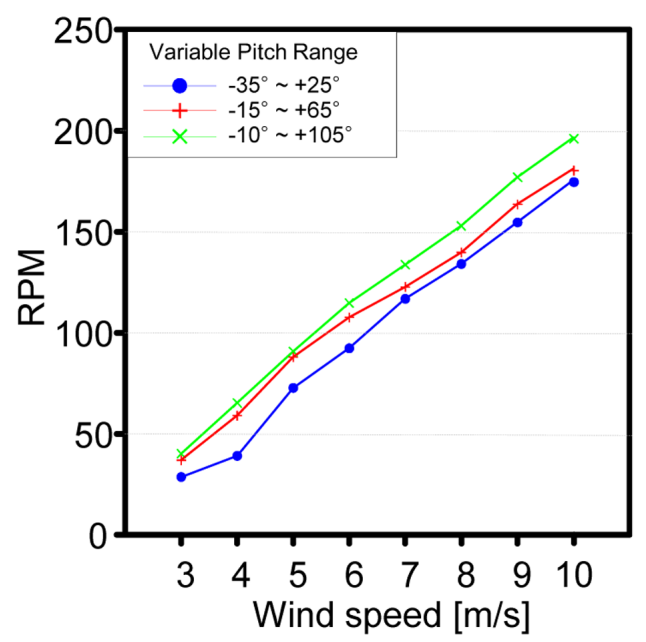

Fig. 8 The RPM by the wind speed following variable-pitch range in no load condition 


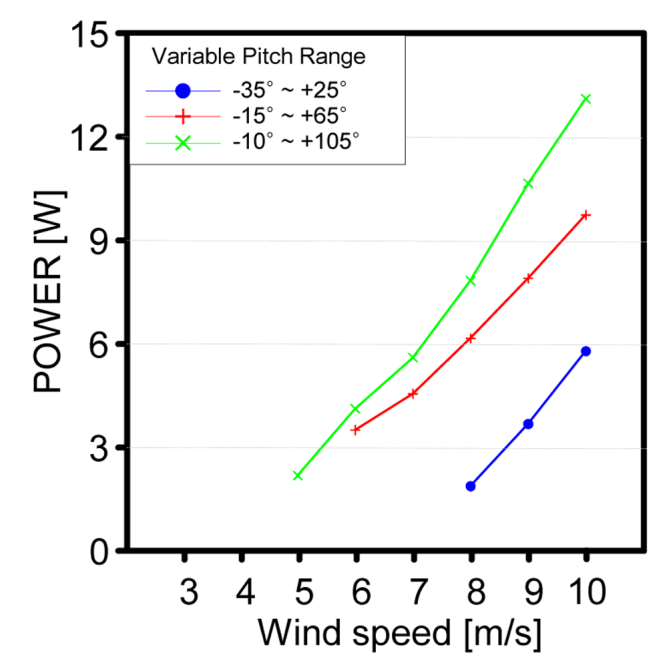

Fig. 9 The power by the wind speed following variable-pitch range in load condition

\section{2 부유식 풍력발전 실험}

해양 공학수조에서 실시한 부유식 풍력발전 실험은 단독 발 전 효율 실험결과 발전 효율이 가장 좋은 피치 가변 범위 $-10^{\circ}$ $+105^{\circ}$ 의 경우에 대해 실시하였다. Fig. 10 은 파랑 조건에 따른 풍력발전기의 RPM응답을 나타낸 것이며, Fig. 11은 부유식 풍 력발전시스템의 규칙파 중 운동응답 이론해석 및 실험결과를 나타낸 그래프이다. Fig. 11에 따르면 구조물의 Heave 운동응답 은 $2.4 \mathrm{sec}$ 의 규칙파에서 가장 크게 나타났으며, Surge와 Pitch 운 동응답은 $3.0 \mathrm{sec}$ 의 규칙파에서 가장 크게 나타났다. Fig. 10 의 풍 력발전기의 RPM응답과 Fig. 11의 구조물의 운동응답을 비교한 결과, 규칙파 실험 범위 중 Surge와 Pitch 운동이 가장 크게 일 어나는 $3.0 \mathrm{sec}$ 의 규칙파에서 RPM응답과 파가 없을 경우의 RPM 응답은 큰 차이를 보이지 않는다. 하지만 Heave운동이 가장 큰 $2.4 \mathrm{sec}$ 의 규칙파에서 RPM응답이 가장 작게 나타난 것을 알 수

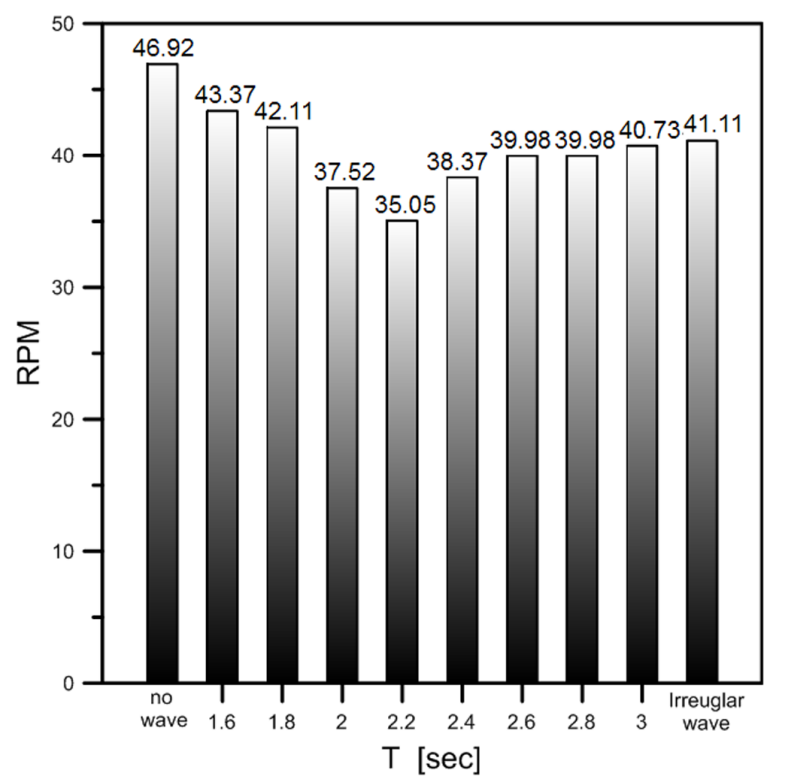

Fig. 10 The RPM responses on each experimental case in $8 \mathrm{~m} / \mathrm{s}$ wind speed
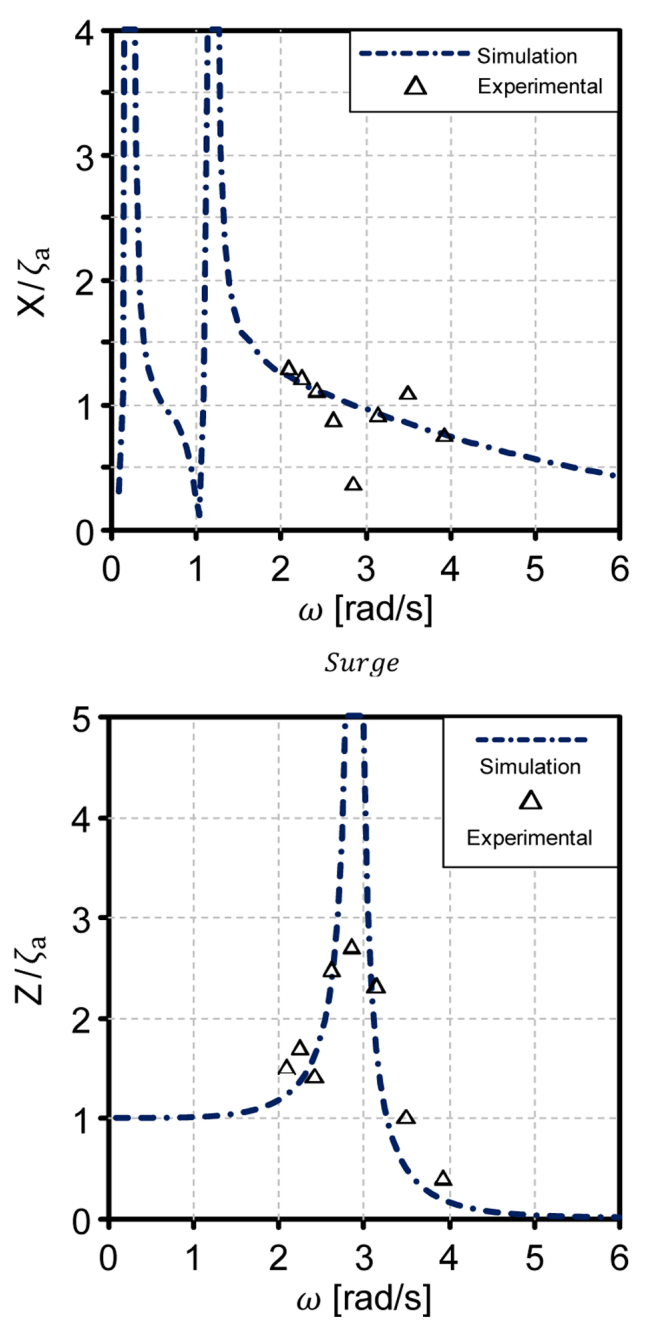

Heave

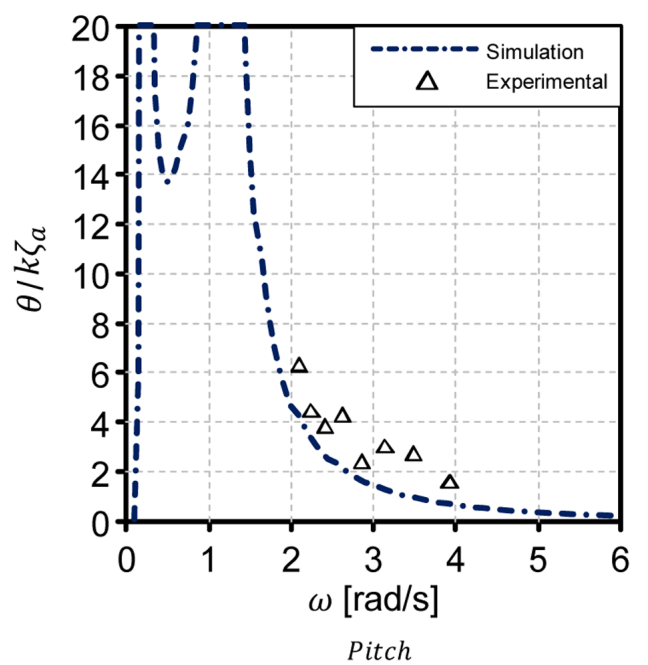

Fig. 11 Dynamic response of simulation and experiment of floating VAWT in regular waves

있다. 이는 바람 발생장치의 바람 출구와 풍력발전기의 높이가 거의 유사하여, 구조물의 상하동요에 의해 풍력발전기가 유효 바람 면적을 벗어나기 때문으로 판단하였다. 또한 단독 발전 효 율 실험의 RPM응답과 Fig. 10 의 부유식 풍력발전실험의 RPM응 
답을 비교하면 부유식 풍력발전실험의 RPM응답결과가 현저히 낮게 나타난다. 이 결과에 대한 이유로, 단독 발전효율 실험에 선 풍력발전기와 바람 발생장치간의 거리가 $1.5 \mathrm{~m}$ 이나, 풍력발 전 실험에선 부유체의 위치유지를 위한 계류시스템 때문에 설 치거리가 $2.8 \mathrm{~m}$ 로 약 2 배 정도 멀어짐에 따라 RPM응답 결과가 약 $75 \%$ 감소하였다. 비록 두 실험을 동일한 풍속에서 수행하였 지만 멀어진 거리로 인한 풍량 감소를 가장 큰 원인으로 판단 하였다. 여기서 풍량이란 바람 발생장치의 덕트를 통해 이동한 공기의 양이다. 부유식 풍력발전 실험의 경우 개방된 공간에서 수행되어 바람의 집중도가 떨어졌기 때문이다.

\section{5. 결 론}

본 연구에서는 가변 피치형 수직축 풍력발전기에 대해 실험 을 통하여 단독 발전 효율을 파악하고, 파랑 및 바람 중 부유체 동적거동과 RPM운동응답을 비교하였다. 각각의 실험을 통하여 얻은 결론은 아래와 같다.

(1) 단독 발전 효율 실험 결과 모든 피치 가변 범위에서 풍동 시스템의 최저 풍속인 $3 \mathrm{~m} / \mathrm{s}$ 에서 기동이 일어남을 확인하였고, 피치 가변 범위 $-10^{\circ} \sim+105^{\circ}$ 에서 최고 효율을 나타내었다.

(2) 부유식 풍력발전 실험결과 Surge와 Pitch 운동이 가장 큰 $3.0 \mathrm{sec}$ 의 규칙파에 대한 RPM응답은, 파가 없는 경우의 RPM 응 답과 큰 차이를 보이지 않았다.

(3) 반면, Heave운동이 가장 큰 $2.4 \mathrm{sec}$ 의 규칙파에 대한 RPM 응답은 모든 실험 case 중 가장 낮게 나타났다. 이는 부유체 Heave운동으로 인해 풍력발전기의 유효 바람 면적을 벗어났기 때문으로 보여 진다.

추후 풍력발전기 블레이드 형상 및 크기에 따른 발전효율에 대한 연구가 필요하다.

\section{References}

Hwang, B.S., 2014. Introduction to Wind Energy and Technology. A-JIN, Korea.

Kim, M.S., Lee, M.S., Kim, M.W., Shin, H.G., 2011. Motion Analysis of 5MW Spar Type Floating Offshore Wind Turbine. The Proceedings of the Society of Naval Architects of Korea, 804-808.

Lee, K.J., 2014. A Study on Characteristics of Electrical and Mechanical Properties for Small-Scaled Wind Turbines (M.S. Thesis). Changwon National University, Korea.

Martin, H.R., 2011. Development of a Scale Model Wind Turbine for Testing of Offshore Floating Wind Turbine Systems. Electronic Theses and Dissertations, The Graduate School of the University of Maine, 1578.

Oh, M.W., Kim, D.H., 2012. Design and Computational Analysis of Small Vertical-Axis Wind Turbine for Ocean Buoy System. Journal of the Wind Engineering Institute of Korea, 16(2), 58-64.

Sheldahl, R.E., Klimas, P.C., 1981. Aerodynamic Characteristics of Seven Symmetrical Airfoil Sections Through Aairfoil Sections Through 180-Degree Angle of Attack for Use in Aerodynamic Analysis of Vertical Axis Wind Turbines. Sandia National Laboratories Energy Report, SAND-80-2114.

Sim, J.P., 2013. Experimental and CFD Analysis of V-Shape Vetrical Axis Wind Turbine (M.Sc. thesis). Gyeongsang National University, Korea. 